\title{
Toxicokinetics of 2,4- and 2,6-toluenediamine in hydrolysed urine and plasma after occupational exposure to 2,4- and 2,6- toluene diisocyanate
}

\author{
Pernilla Lind, Marianne Dalene, Gunnar Skarping, Lars Hagmar
}

\begin{abstract}
Objectives-To assess the toxicokinetics of 2,4- and 2,6- toluenediisocyanate (TDI) in chronically exposed subjects.

Methods-Blood and urine, from 11 workers at two flexible foam polyurethane production plants, were sampled. By gas chromatography-mass spectrometry (GC-MS) 2,4- and 2,6-toluene diamine (TDA) were measured as pentafluoropropionic anhydride (PFPA) derivatives after acidic hydrolysis of plasma (P-TDA, $\mathrm{ng} / \mathrm{ml}$ ) and urine (U-TDA, $\mu \mathrm{g} / \mathrm{h}$ ).

Results-In one of the plants the P-2,4TDA concentrations were $0.4-1 \mathrm{ng} / \mathrm{ml}$ before a four to five week holiday and $0.2-0.5 \mathrm{ng} / \mathrm{ml}$ afterwards. The corresponding values for $P-2,6-T D A$ were $2-6$ and $0 \cdot 5-2 \mathrm{ng} / \mathrm{ml}$ respectively. In the other
\end{abstract} plant the P-2,4-TDA concentrations were 2-23 $\mathrm{ng} / \mathrm{ml}$ before the holiday and 0.5-6 $\mathrm{ng} / \mathrm{ml}$ afterwards and the $P-2,6-T D A$ concentrations were 7-24 $\mathrm{ng} / \mathrm{ml}$ before and 3-6 ng/ml afterwards. The P-2,4-TDA concentrations were $2-24 \mathrm{ng} / \mathrm{ml}$ before a 12 day holiday, and $1-14 \mathrm{ng} / \mathrm{ml}$ afterwards. The corresponding values for $P$ 2,6-TDA were 12-29 and 8-17 $\mathrm{ng} / \mathrm{ml}$, respectively. The urinary elimination rates (U-TDA, $\mu \mathrm{g} / \mathrm{h}$ ) for 2,4-TDA before the holiday were $0.04-0.54$ and $0.02-0.18$ $\mu \mathrm{g} / \mathrm{h}$ afterwards. The corresponding values for 2,6-TDA were $0 \cdot 18-0.76 \mu \mathrm{g} / \mathrm{h}$ before and $0.09-0.27 \mu \mathrm{g} / \mathrm{h}$ after the holiday. The half life in urine ranged between 5.8 and 11 days for 2,4- and 2,6-TDA. The differences in exposure were reflected by the P-TDA concentrations. The mean half life in plasma was 21 (range 14-34) days for 2,4-TDA and $21(16-26)$ days for 2,6-TDA. The TDI air concentrations varied between 0.4 and $4 \mu \mathrm{g} / \mathrm{m}^{3}$ in one plant and in the other between 10 and $120 \mu \mathrm{g} / \mathrm{m}^{3}$.

Conclusions-The half life in plasma of chronically exposed workers for 2,4-and 2,6-TDA was twice as long as for volunteers with short term exposure. An indication of a two phase elimination pattern in urine was found. The first phase was related to the more recent exposure and the second, much slower one was probably related to release of TDA in urine from TDI adducts in the body.

(Occup Environ Med 1996;53:94-99)
Keywords: toluenediisocyanate; biomarkers; toxicokinetics; gas chromatography-mass spectrometry

Toluenediisocyanate (TDI) is an important industrial chemical, used in the production of polyurethane (PUR) polymers. Commercially used TDI contains both the 2,4- and 2,6-TDI isomers in $80: 20$ or $65: 35$ ratios.

In high concentrations TDI may cause irritation of the mucous membranes, have sensitising properties, and may also cause asthma and possibly a progressive impairment of pulmonary function..$^{1-3}$ Moreover, TDI is carcinogenic to animals ${ }^{4}$ but occupational exposure in polyurethane foam manufacturing has, to date, not been associated with an increased risk of cancer. ${ }^{5-7}$

The Swedish occupational exposure limit (OEL) for an eight hour working day is $40 \mu \mathrm{g}$ of $\mathrm{TDI} / \mathrm{m}^{3}$.

Several methods for determination of isocyanates in air have been described. ${ }^{8-10}$ Methods based on sampling with impinger flasks containing an amine reagent followed by liquid chromatography (LC) result in highly sensitive measurements. Short term exposure measurements are therefore possible, but tedious. In practice it is difficult to monitor the airborne exposure over several days.

During the past few years methods for biological monitoring of isocyanates have been presented. These methods are based on assessment of the corresponding amines, 2,4and 2,6-toluenediamine (2,4- and 2,6-TDA), in hydrolysed urine or plasma. The TDA is treated with pentafluoropropionic anhydride (PFPA) to form amide derivatives $(2,4-$ and 2,6-TDAPFPA). The derivatives were then measured with gas chromatography (GC) and mass spectrometry (MS). Electron impact and chemical ionisation with selected ion monitoring have been used. ${ }^{11}$ In a recent study, performed at our laboratory, chemical ionisation with ammonia was used to monitor negative ions, a detection limit of about $1 \mathrm{fg}$ injected (50 ng TDA/l of urine or plasma) was found. ${ }^{12}$

Controlled human TDI exposure studies have been performed where human volunteers have been exposed to gaseous TDI at the Swedish OEL and half the OEL for eight hours. ${ }^{11} 1314$ An initial rapid urinary elimination half life of two to five hours and a later slower phase of more than six days was found. The elimination half life in plasma was estimated to be about 10 days. ${ }^{14}$ An association between TDI in air and the urinary excretion of TDA 
was found, and $8 \%-18 \%$ of the inhaled TDI dose was measured as TDA in hydrolysed urine.

Among workers of TDI flexible foam an association was found between the TDI exposure and TDA in hydrolysed urine. In each exposed subject, the plasma concentrations of TDA were stable over the study period but great variations were found between people. ${ }^{15} 16$

The aim of this study was to elucidate the toxicokinetics of 2,4-TDI and 2,6-TDI in workers exposed long term, to give a better basis for biomonitoring methods of occupational exposure. We have therefore studied the corresponding amines, 2,4-TDA and 2,6$\mathrm{TDA}$, in plasma (P-TDA $\mathrm{ng} / \mathrm{ml}$ ) and urine (U-TDA $\mu \mathrm{g} / \mathrm{h}$ ) from TDI foam workers before, during, and after exposure free periods.

\section{Material and methods}

A TRIO 1000 quadruopole mass spectrometer connected to a GC 8000 gas chromatograph (Fisons Instruments, Altrincham, Cheshire, England) equipped with an A200S auto sampler (Milan, Italy) was used. When the TDAPFPA derivatives were measured the ions monitored were $\mathrm{m} / \mathrm{z}=394$ corresponding to the $M-20$ ions and the $m / z=397$ ions of the trideuterium labelled internal standard ( $M=$ molecular weight). ${ }^{12}$

The injector temperature was $290^{\circ} \mathrm{C}$, and the starting temperature of the column oven was isothermal at $110^{\circ} \mathrm{C}$ for one minute, then raised at $15^{\circ} \mathrm{C}$ a minute to $280^{\circ} \mathrm{C}$ where it was kept for two minutes. The split exit valve was kept closed for one minute after injection. The temperature of the ion source was $230^{\circ} \mathrm{C}$ and the GC-MS interface temperature was $280^{\circ} \mathrm{C}$. The capillary inlet pressure of helium was 0.8 $\mathrm{kg} / \mathrm{m}^{3}$. The solvent delay was set to $2.9 \mathrm{~min}-$ utes. The instrument was used in the chemical ionisation mode with negative ion (NCI) monitoring and ammonia as the reagent gas. The dwell time for each of the ions were $0.2 \mathrm{~s}$ and the delay between scans was $0.02 \mathrm{~s}$. The pressure in the ion source was, in the case of chemical ionisation with ammonia and negative ion monitoring, kept at about $2 \times 10^{-4}$ mbar. The emission current was $200 \mathrm{mV}$ and the electron energy $60 \mathrm{eV}$.

A Millipore Waters (Millipore-Waters, Milford, MA, USA) 600 multisolvent delivery system, a Waters 712 WISP with variable injection volume, a Waters 490 programmable multiwavelength detector and a three channel SE-130 (ABB Goerz AG, Vienna, Austria). The mobile phase $(1 \mathrm{ml} / \mathrm{min})$ consisted of $70 \%$ acetonitrile and $30 \%$ water with $3 \%$ triethylamine adjusted to $\mathrm{pH} 3$ with phosphoric acid.

Gil air personal air sampler (Gilian, Instruments Corporation, USA ) and $30 \mathrm{ml}$ midget impingers were used for air sampling.

Fused silica capillary columns with chemically bounded stationary phases, DB-5 J and $\mathrm{W}$ Scientific (Folsom, CA, USA) $30 \mathrm{~m} \times 0.25 \mathrm{~mm}$ ID with a film thickness of
$0.25 \mu \mathrm{m}$ were used for the GC-MS measurements. Columns for high performance liquid chromatography (HPLC) were of stainless steel $(200 \mathrm{~mm}, 5 \mathrm{~mm}$ ID), packed with $5 \mu \mathrm{m}$ Nucleosil C18 (Macherey-Nagel, Düren, Germany).

The 2,4-TDA and 2,6-TDA were obtained from Fluka (Buchs, Switzerland); 2,4-TDI and 2,6-TDI, $\mathrm{HCl}, \mathrm{NaOH}$ and $\mathrm{K}_{2} \mathrm{HPO}_{4}$, from E Merck (Darmstadt, Germany); PFPA from Pierce (Rockford, IL, USA); toluene and HPLC grade acetonitrile from Lab-Scan (Dublin, Ireland); triethylamine (99\%) from Janssen (Beerse, Belgium); trideuterated 2,4- and 2,6-TDDA $\left(\mathrm{CD}_{3} \mathrm{C}_{6} \mathrm{H}_{3}\left[\mathrm{NH}_{2}\right]_{2}\right)$ and 9-(N-methyl amino-methyl)-anthracene hydrochloride (MAMA) from Synthelec (Lund, Sweden).

\section{PROCEDURE}

Preparation of standard solutions

Standard solutions of 2,4- and 2,6- TDA were prepared by dissolving accurately weighed amounts in $0.1 \mathrm{M} \mathrm{HCl}$. The TDI standard solutions were prepared by dissolving TDI in isooctane and further diluting this with isooctane.

Sampling, handling, and storing of biological samples

All urine was collected in polyethylene bottles. The density, creatinine concentration, $\mathrm{pH}$, and total volume of the urine samples were measured. Blood was sampled in heparinised tubes (Venoject). Plasma was separated. The urine and blood plasma samples were kept frozen at $-20^{\circ} \mathrm{C}$ until analysis.

\section{Work up procedure for biological samples}

One $\mathrm{ml}$ of urine or plasma was hydrolysed at $100^{\circ} \mathrm{C}$ for 16 hours with $1.5 \mathrm{ml}$ of $6 \mathrm{M} \mathrm{HCl}$, containing trideuterated 2,4- and 2,6-TDA $(0.5+0.5 \mu \mathrm{g} / \mathrm{l})$ as internal standards. With PFPA as derivatisation reagent, amide derivatives were formed. Two aliquots from each sample were then worked up and two GC-MS measurements were performed for each aliquot. The average of the four GC-MS measurements was used as an estimate of U-TDA and P-TDA. ${ }^{12} 15$

\section{Analysis of TDI in air}

The concentrations of TDI in air were measured with impinger flasks containing the MAMA amine reagent dissolved in toluene at a concentration of $1 \times 10^{-4} \mathrm{M}^{8}{ }^{8}$ The air speed was $11 / \mathrm{min}$ and the sampling time varied between five and 50 minutes. After sampling, the toluene solution containing the formed urea derivatives was evaporated to dryness. The dry residue was dissolved in $1 \mathrm{ml}$ of acetonitrile:water $(70 \%: 30 \% \mathrm{v} / \mathrm{v})$. Peak height measurements were performed with LC-UV (ultraviolet) and duplicate injections were made for each concentration. The TDI air concentrations were measured on one occasion in both plants $I(n=14)$ and II $(n=42)$. Personal and stationary air samples were obtained at both plants.

The TDI standard solutions were prepared 
by dissolving TDI in isooctane. Toluene solutions containing the MAMA reagent were spiked with 2,4- and 2,6-TDI to five different concentrations in the range of $10-100 \mathrm{ng} / \mathrm{ml}$. The work up procedure was then performed. The linear calibration plot obtained passed virtually through the origin and the correlation coefficient was 0.998 .

PROCESS

Two plants, I and II, produced flexible polyurethane foam in continuous foam blocks. Both plants used an 80:20 mixture of 2,4-TDI and 2,6-TDI. The TDI was mixed with a polyol component and was poured, with a foaming nozzle, on to moving kraft paper. The polymerisation reaction continued for several hours in a ventilated curing tunnel. Normally one foam block was cured in the morning and one in the afternoon. Plants I and II had similar production techniques and products.

SUBJECTS, EXPOSURE, AND SAMPLE

COLLECTION

Air samples were taken during foaming some days before the studies started. The duration of the foaming process was two to three hours a day. The workers were wearing personal respiratory protection devices when the TDI concentrations were subjectively estimated to be very high. During the rest of the day the workers were occupied with preparation of the foaming apparatus which caused very little exposure.

Five workers (A-E) from plant I and six workers $(\mathrm{F}-\mathrm{K})$ from plant II participated in the studies. Subject A worked close to the foaming nozzle, and $C$ and D worked at the beginning of the curing tunnel. Subjects $B$ and $E$ worked in the tunnel, and $E$ also cut ready made PUR block into pieces. Subjects F and J worked close to the foaming nozzle, subjects I, $G$ and $K$ worked in the tunnel and subject $H$ worked at cutting ready made PUR blocks into pieces.

All workers worked from 700 am to 400 pm five days a week. Respiratory protection devices were only used during short periods when they were working in the curing tunnel.

\section{Study 1}

Five workers (A-E) from plant I and five workers (F, G, H, J, and $\mathrm{K}$ ) from plant II participated in the study. Workers were studied before and after a four to five week summer holiday. Blood samples were taken before the holiday, immediately before returning to work, and two to three times after the holiday.

Study 2

Four workers (F-I) from plant II were studied, before and after a 12 day Christmas holiday. Blood and urine samples were taken seven days and one day before the holiday, after five days of holiday, at the end of the holiday, and 31 days after the end of the holiday. At each blood sampling occasion, all urine produced during the preceding 24 hours was collected. A urine sample could not be obtained from one of the subjects $(\mathrm{H})$ on the last sampling occasion.

\section{HEALTH EXAMINATION}

All 11 subjects were interviewed by a physician (LH) for a health history. One of the subjects had well controlled diabetes mellitus, and two of the others wheezed when they had colds, but had no work related symptoms. Pulmonary function tests for vital capacity and forced expiratory volume in one second were carried out with a vitalograph spirometer, and showed no gross abnormalities. None was sensitised against TDI according to the results of a skin prick test with a conjugate of TDI and human serum albumin. Venous blood samples showed slightly enhanced $\gamma$-glutamyl-transferase concentrations in serum in two of the workers $(F, G)$.

\section{Results}

AIRBORNE EXPOSURE TO TDI

The TDI concentration in plant I varied between 0.4 and $4 \mu \mathrm{g} / \mathrm{m}^{3}$ and the relative concentration of 2,4- and 2,6-TDI varied between $60 \% / 40 \%$ and $5 \% / 95 \%$. The TDI concentration in plant II varied between 10 and 120 $\mu \mathrm{g} / \mathrm{m}^{3}$, the relative concentration of $2,4-$ and $2,6-$ TDI varied between $65 \% / 35 \%$ and $30 \% / 70 \%$.

\section{Study 1}

The exposure levels in plant I were lower than in plant II. This was reflected by the P-TDA concentrations. Among the workers in plant I, the P-2,4-TDA varied between 0.4 and 1.3 $\mathrm{ng} / \mathrm{ml}$ before the summer holiday, and between 0.2 and $0.5 \mathrm{ng} / \mathrm{ml}$ after the holiday (fig 1A). The P-2,6-TDA varied between $1 \cdot 8$ and $5.6 \mathrm{ng} / \mathrm{ml}$ before the summer holiday, and between 0.5 and $2.0 \mathrm{ng} / \mathrm{ml}$ after the holiday (fig 1B). Worker D was only occasionally present in the production area. Workers B and E worked only for 12 days after the summer holiday before they had another week off.

The P-2,4-TDA in the five workers from plant II varied between 2 and $23 \mathrm{ng} / \mathrm{ml}$ before the summer holiday and between 0.5 and 6.0 $\mathrm{ng} / \mathrm{ml}$ after the holiday (fig $1 \mathrm{C}$ ). The P-2,6TDA before the summer holiday varied between 7.0 and $23 \mathrm{ng} / \mathrm{ml}$, and after the summer holiday between 3.0 and $6.0 \mathrm{ng} / \mathrm{ml}$ (fig 1D). Worker $\mathrm{K}$ only worked for three days after the holiday, which is obvious from the small increase in P-TDA after the holiday and the later decrease in TDA concentrations (fig $1 \mathrm{C}$ and $\mathrm{D})$. Worker $\mathrm{H}$ had about a seven times higher concentrations of 2,6-TDA than 2,4TDA. This can be explained by his working task at the end of the process where the 2,6-/ $2,4-T D I$ ratio in air is very high.

\section{Study 2}

Among the workers in plant II the P-2,4-TDA varied between 2.0 and $24 \mathrm{ng} / \mathrm{ml}$ before the holiday (Christmas) and between 1.0 and 14 $\mathrm{ng} / \mathrm{ml}$ after the holiday. The P-2,6-TDA varied between 12 and $29 \mathrm{ng} / \mathrm{ml}$ before the holiday and between 8.0 and $17 \mathrm{ng} / \mathrm{ml}$ after the holiday (fig 2). Urine and plasma samples were also taken 31 days after the exposure free period. The U-TDA and P-TDA were not the 
Figure 1 The concentrations of TDA in hydrolysed plasma ( $\mathrm{ng} / \mathrm{ml})$ before and after the summer holiday. (A) P-2,4-TDA, (B) P-2,6-TDA from the workers $A-E$. (C) $P-2,4$ $T D A$, and (D) $P-2,6-$ TDA from the workers $F$, $G, H, \mathcal{F}$ and $K$. Day 0 is the first day of the holiday. Time $0=$ first working day after the holiday.
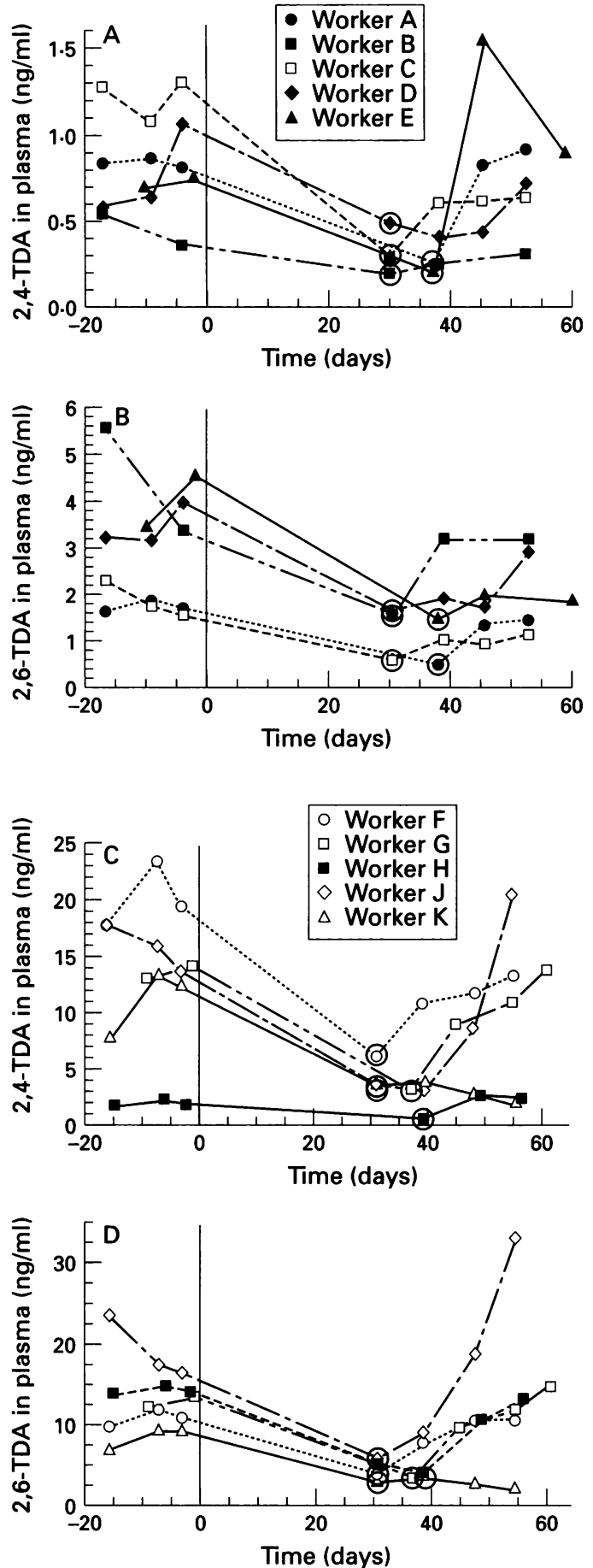

Table 2 Half life of 2,4-and 2,6-TDA in hydrolysed plasma (days)

\begin{tabular}{lllll}
\hline Plant & Worker & TDA Isomer & Study I & Study II \\
\hline I & A & $2,4-$ & 22 & \\
& & $2,6-$ & 20 & \\
& B & $2,4-$ & 34 & \\
& C & $2,6-$ & 26 & \\
& & $2,4-$ & 14 & \\
& D & $2,6-$ & 20 & \\
& E & $2,4-$ & 26 & \\
& II & $2,4-$ & 22 & \\
& F & $2,6-$ & 20 & \\
& & $2,4-$ & 22 & 23 \\
& G & $2,6-$ & 19 & 26 \\
& & $2,6-$ & 21 & 15 \\
& H & $2,4-$ & 19 & 16 \\
& & $2,6-$ & 22 & 14 \\
& I & $2,4-$ & 20 & 16 \\
& J & $2,6-$ & & 30 \\
& K & $2,4-$ & 17 & 23 \\
& & $2,4-$ & 20 & \\
\hline
\end{tabular}

same as before the holiday, due to reduced production at the plant.

The elimination rate before the holiday varied for 2,4-TDA in urine among the workers between 0.04 and $0.54 \mu \mathrm{g} / \mathrm{h}$ and for $2,6-\mathrm{TDA}$ between 0.18 and $0.76 \mu \mathrm{g} / \mathrm{h}$. After the holiday and immediately before the start of exposure the elimination rates were for 2,4-TDA, between 0.02 and $0.18 \mu \mathrm{g} / \mathrm{h}$ and for 2,6-TDA, between 0.09 and $0.27 \mu \mathrm{g} / \mathrm{h}$ (table 1 ).

HALF LIFE OF TDA IN PLASMA

The P-2,4-TDA and P-2,6-TDA, in study I, were used to estimate half life $\left(t_{1 / 2}\right)$ in plasma $\left(\mathrm{Pt}_{1 / 2}\right)$. The P-TDA before the holiday and the $\mathrm{P}-\mathrm{TDA}$ at the end of the holiday were used in the calculations assuming a log linear excretion pattern. Data on P-TDA from samples drawn before, during, and at the end of the holiday (study II) were also used to calculate $\mathrm{Pt}_{1 / 2}$ (table 2). To estimate the $\mathrm{Pt}_{1 / 2}$ the natural logarithms of the concentrations were plotted against time. The best linear plots were made and the slope of each plot was found. The $\mathrm{Pt}_{1 / 2}$ was calculated by dividing $\ln 2$ by the slope. The Pt varied between 14 and 34 days for P2,4-TDA and 16 and 26 days for P-2,6-TDA. The mean was 21 days for both 2,4- and 2,6TDA. A weak non-significant negative correlation was indicated $(r s=-0.35, \mathrm{P}=0.27)$ between P-2,4-TDA before the holiday and $t_{1 / 2}$. No such association was seen for 2,6TDA.

Table 1 Mean elimination rate of 2,4- and 2,6-TDA in hydrolysed urine $(\mu g / h)$ from workers $F, G, H$ and $I$ at plant II-study 2: all urine samples were obtained during about $24 \mathrm{~h}$ at each sampling occasion (each urine sample was analysed separately and the mean elimination rate during the period was calculated)

\begin{tabular}{|c|c|c|c|c|c|c|}
\hline Worker & $\begin{array}{l}T D A \\
\text { Isomer }\end{array}$ & $\begin{array}{l}\text { Work } \\
-7 \\
\text { days }\end{array}$ & $\begin{array}{l}\text { Work } \\
-1 \\
\text { day }\end{array}$ & $\begin{array}{l}\text { Holiday } \\
5 \\
\text { days }\end{array}$ & $\begin{array}{l}\text { Holiday } \\
12 \\
\text { days }\end{array}$ & $\begin{array}{l}\text { Work } \\
43 \\
\text { days }\end{array}$ \\
\hline \multirow[t]{2}{*}{ F } & $2 \cdot 4$ & $0 \cdot 22$ & $0 \cdot 13$ & 0.072 & 0.072 & 0.063 \\
\hline & $2 \cdot 6$ & 0.30 & $0 \cdot 18$ & 0.0 & & 0.070 \\
\hline \multirow[t]{2}{*}{ G } & $2 \cdot 4$ & 0.48 & 0.54 & 0.23 & 0.18 & 0.36 \\
\hline & $2 \cdot 6$ & 0.66 & 0.76 & $0 \cdot 34$ & $0 \cdot 27$ & 0.49 \\
\hline \multirow[t]{2}{*}{$\mathrm{H}$} & $2 \cdot 4$ & 0.039 & 0.047 & 0.020 & 0.022 & \\
\hline & $2 \cdot 6$ & 0.50 & 0.62 & 0.25 & 0.25 & \\
\hline \multirow[t]{2}{*}{1} & $2 \cdot 4$ & 0.20 & & $0 \cdot 11$ & 0.091 & 0.12 \\
\hline & $2 \cdot 6$ & & 0.33 & 0.18 & 0.13 & 0.19 \\
\hline
\end{tabular}

Figure 2 The concentrations of TDA in hydrolysed plasma ( $\mathrm{ng} / \mathrm{ml})$ before, during, and after the Christmas holiday for the workers F-I. Day 0 is the first day of the holiday. 
HALF LIFE OF TDA IN URINE

The U-2,4-TDA and U-2,6-TDA in study II were estimated. The $t_{1 / 2}$ in urine $\left(\mathrm{Ut}_{1 / 2}\right)$ was calculated in the same way as the $\mathrm{Pt}_{1 / 2}$, and

A
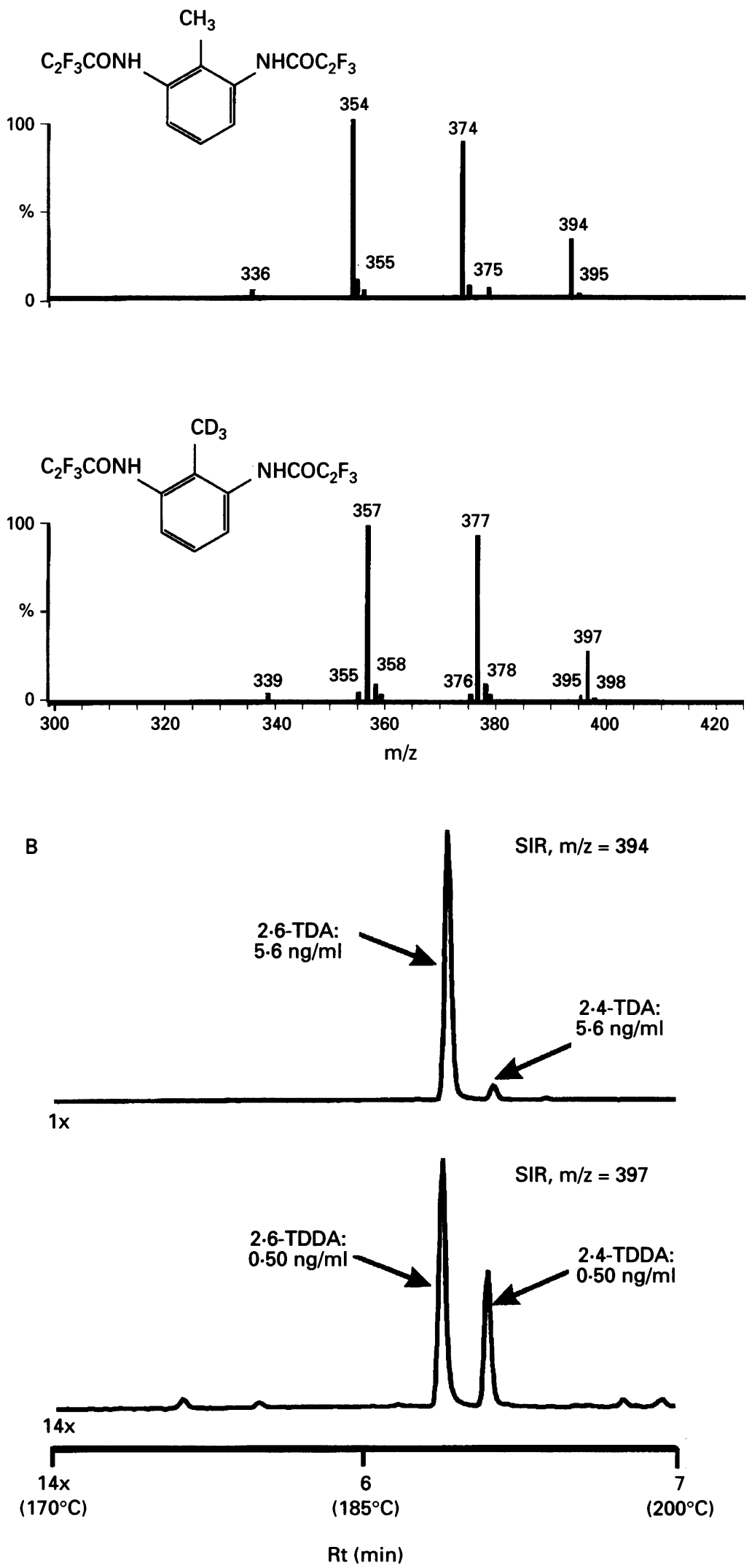

Figure 3 (A) GC-MS-NCI, with ammonia, of the PFPA derivatives of 2,6-TDA and 2,6-TDDA. The injected amount was about 20 ng of each derivative. (B) $A$ hydrolysed plasma sample from a worker exposed to TDI. The chromatograms shows the $\mathrm{m} / \mathrm{z}$ $=394(M-20)$ ions of the 2,6-and 2,4-TDA-PFPA and the $\mathrm{m} / \mathrm{z}=397$ (M-20) ions of the 2,6-and 2,4-TDDA-PFPA derivatives. The 2,6-and 2,4-TDA peaks correspond to about 5.6 and $0.56 \mathrm{ng} / \mathrm{ml}$, respectively. The concentrations of 2,6- and 2,4-TDDA were 0.5 $\mathrm{ng} / \mathrm{ml}$. varied between $5 \cdot 8$ and 11 days for $2,4-$ TDA and 6.4 and 9.3 days for 2,6 -TDA.

GAS CHROMATOGRAPHY-MASS SPECTROMETRY Figure 3A shows that the most abundant ions in the GC-MS-NCI, with ammonia, mass spectra of 2,6- and 2,4-TDA-PFPA are the $\mathrm{m} / \mathrm{z}=\mathrm{M}-\mathrm{n} \times 20$ ions. The intensity varies with the temperature of the ion source and the ammonia pressure. ${ }^{12}$ The instrumental detection limit was 1-5 fg, corresponding to less than $0.05 \mu \mathrm{g}$ TDA $/ 1$ in human urine or plasma. Figure 3B shows that for both 2,4-and 2,6-TDA-PFPA selective and sensitive measurements are possible. Calibration plots for human urine and plasma spiked with 2,4- and $2,6-T D A$ were made in the range $0-50 \mu \mathrm{g} / 1$. The calibration plots were linear in the range $0-10 \mu \mathrm{g} / 1$. In the range $10-50 \mu \mathrm{g} / 1$ the calibration plots were not linear and a polynomial approximation was applied. Samples $<10 \mu \mathrm{g} / 1$ were measured with a linear calibration plot. The non-linear calibration plot is due to the low concentration of internal standard. The low concentration of the internal standard was necessary to be able to measure low concentrations of TDA. When the mean from the work up procedure of the two aliquots from the same sample differed by more than $40 \%$ the result was disregarded and the procedure was done over again.

\section{Discussion}

Analysis of TDI in air with the use of the impinger technique may indicate the order of magnitude of the biologically relevant exposure, but will not provide a more precise estimate. Airborne exposure data therefore rather reflects differences between production sites. The lower airborne exposures found in plant I were most likely due to a better ventilation system.

The relative 2,4-TDI and 2,6-TDI concentrations in the air close to the foaming nozzle were close to those in the bulk. The ratio decreased at the end of the tunnel due to the higher reactivity of the 2,4-TDI isomer.

The workers exposed to TDI with a low 2,4-TDI/2,6-TDI ratio, also showed a low P2,4-TDA/P-2,6-TDA ratio. This indicates that the two TDI isomers follow a similar metabolic pattern.

Half lives of 2,4-and 2,6-TDA in plasma, of about 10 days, have already been found for volunteers exposed short term to TDI in an exposure chamber. ${ }^{14}$ In the present study, of workers exposed long term, the mean $\mathrm{P}-\mathrm{t}_{1 / 2}$ was 21 days for both isomers. The $P-t_{1 / 2}$ does not seem to be strongly affected by the P-TDA concentrations, but the limited number of subjects studied does not exclude minor associations. The difference in $\mathrm{P}-\mathrm{t}_{1 / 2}$ between the TDI workers and the volunteers can be explained by several factors. The volunteers were exposed only to pure monomeric gaseous TDI for a few days. The workers were also exposed to other components, such as catalysts, polyols, etc, and probably also to aerosols containing not only TDI monomers 
but also products resulting from partly reacted isocyanates and polyols. The biodegradation of TDI aerosols is at present completely unknown. Aerosol particulates will probably also deposit more distally in the respiratory system than the isocyanate gas phase, which may result in different elimination kinetics. We cannot, however, exclude the possibility that chronically exposed workers will metabolise TDI slightly differently compared with the volunteers. As the $t_{1 / 2}$ in plasma is relatively long, the plasma concentration may reflect the exposure during the past few months and the exact sampling time is not crucial. The P-TDA seems to have a potential to be a both reliable and convenient biomarker of long term exposure to TDI. Moreover, the dose independent elimination pattern in plasma, and similar kinetics for both isomers, adds to the feasibility of this biomarker.

In three earlier studies, two that investigated exposed volunteers and one exposed workers, we have shown that the U-TDA is mainly related to the TDI exposure during the past few hours. ${ }^{13-15}$ The present study gives an indication of a second elimination phase. Table 1 shows that U-TDA declines at a much slower rate than the $t_{1 / 2}$ of two to five hours found in earlier studies. The first elimination phase is related to the more recent exposure and the second is probably related to release of TDI adducts in the body into the urine. Albumin adducts are probably built up during a prolonged exposure and will therefore not be seen in short term exposures of volunteers (to be published).

This work was supported by grants from the Swedish Work Environment Fund and the Medical Faculty, Lund University. We thank Margareta Kajanus and Mikael Adamsson for valuable technical assistance.

1 Banks DE, Butcher BT, Salviaggio JE. Isocyanate-induced respiratory disease. Ann allergy 1986;57:389-98.

2 Cartier A, Grammer L, Malo JL, Lagier F, Ghezzo H, Harris $K$, Patterson $R$. Specific serum antibodies against isocyanates: assosiation with occupational asthma. $\mathcal{F}$
Allergy Clin Immunol 1989;84:507-14.

3 Hagmar L, Nielsen J, Skerfving S. Clinical features and epidemiology of occupational obstructive respiratory disease caused by small molecular weight organic chemicals. Monogr Allergy 1987;21:42-58.

4 National Toxicology Program. Toxicology and carcinogenesis studies of commercial grade 2,4(80\%)-and 2,6(20\%)-toluene diisocyanate (CAS No. 26471-62-5) in F344/N rats and B6C3F1 mice (gavage studies). Research Triangle and B6C3F1 mice (gavage studies). Research Triangle Park, 1986. (Technical Report No 251, NIII Publ No 86-2507.)

5 Hagmar L, Strömberg U, Welinder H, Mikoczy Z. Incidence of cancer and exposure to toluene diisocyanate and methylene diphenyldiisocyanate: a cohort based case-referent study in the polyurethane foam manufacturing industry. Br f Ind Med 1993;50:1003-7.

6 Hagmar L, Welinder H, Mikoczy Z. Cancer incidence and mortality in the Swedish polyurethane foam manufacturing industry. $\mathrm{Br} \mathcal{F}$ Ind Med 1993;50:537-43.

7 Sorahan T, Pope D. Mortality and cancer morbidity of production workers in the United Kingdom flexible polyurethane foam industry. $\mathrm{Br} F$ Ind Med 1993;50: polyureth

8 Sangö C, Zimerson E. A new reagent for determination of isocyanates in working atmospheres by HPLC using UV or fluorescence detection. Fournal of Liquid Chromatography 1980;3:971-90.

9 Skarping G, Renman L, Sangö C, Mathiasson L, Dalene M. Capillary gas chromatographic method for the determination of complex mixture of isocyanates and amines. f Chromatogr 1985;346:191-204.

10 Lesage J, Goyer N, Desjardins F, Vincent JY, Perrault G. Workers exposure to isocyanates. Am Ind Hyg Assoc $\mathrm{f}$ 1992;53:146-53.

11 Sandström JF, Skarping G, Dalene M. Chromatographic determination of amines in biological fluids with special references to the biological monitoring of isocyanates and references to the biological monitoring of isocyanates and amines: II. Determination of 2,4- and 2,6-toluenediamine in human urine using capillary gas chromatograthe biological monitoring of exposure to toluene diisocyanates. $₹$ Chromatogr 1989;479:135-43.

12 Skarping G, Dalene M, Lind P. Determination of toluenediamine isomers using capillary gas chromatography and selected ion monitoring, by special reference to the biological monitoring of 2,4- and 2,6-toluenediisocyanate. f Chromatogr 1994;663:199-210.

13 Brorson T, Skarping G, Sangö C. Biological monitoring of isocyanates and related amines: IV. 2,4- and 2,6-toluenediamine in hydrolysed plasma and urine after test-chamber diamine in hydrolysed plasma and urine after test-chamber
exposure of humans to 2,4- and 2,6-toluene diisocyanate. Int Arch Occup Environ Health 1991;63:253-9.

14 Skarping G, Brorson T, Sangö C. Biological monitoring of diisocyanates and related amines: III. Test chamber exposure of humans to toluene diisocyanate (TDI). Int Arch Occup Environ Health 1991;63:83-8.

15 Persson P, Dalene M, Skarping G, Adamsson M, Hagmar L. Biological monitoring of occupational exposure to toluene diisocyanate: measurement of toluenediamine in toluene dissocyanate: measurement of toluenediamine in mass spectrometry $B r f$ Ind Med 1993;50:1111-8.

16 Maitre A, Berode M, Perdrix A, Romazini S, Savolainen H. Biological monitoring of occupational exposure to toluene diisocyanate. Int Arch Occup Environ Health 1993;65:97-100. 